Article

\title{
Polyamide 11/Poly(butylene succinate) Bio-Based Polymer Blends
}

\author{
Maria Laura Di Lorenzo ${ }^{1, *}$, Alessandra Longo ${ }^{1,2}$ and René Androsch ${ }^{3}$ \\ 1 Institute of Polymers, Composites and Biomaterials (CNR), Via Campi Flegrei, 34, 80078 Pozzuoli (NA), Italy \\ 2 Department of Chemical, Materials and Production Engineering, University of Naples "Federico II", P.le \\ Tecchio 80, 80125 Napoli, Italy \\ 3 Interdisciplinary Center for Transfer-oriented Research in Natural Sciences, Martin Luther University \\ Halle-Wittenberg, D-06099 Halle/Saale, Germany \\ * Correspondence: dilorenzo@ipcb.cnr.it
}

Received: 24 July 2019; Accepted: 29 August 2019; Published: 3 September 2019

check for updates

\begin{abstract}
The manuscript details the preparation and characterization of binary blends of polyamide 11 (PA 11) and poly(butylene succinate) (PBS), with PA 11 as the major component. The blends are fully bio-based, since both components are produced from renewable resources. In addition, PBS is also biodegradable and compostable, contrarily to PA 11. In the analyzed composition range (up to $40 \mathrm{~m} \%$ PBS), the two polymers are not miscible, and the blends display two separate glass transitions. The PA 11/PBS blends exhibit a droplet-matrix morphology, with uniform dispersion within the matrix, and some interfacial adhesion between the matrix and the dispersed droplets. Infrared spectroscopy indicates the possible interaction between the hydrogens of the amide groups of PA 11 chains and the carbonyl groups of PBS, which provides the compatibilization of the components. The analyzed blends show mechanical properties that are comparable to neat PA 11, with the benefit of reduced material costs attained by addition of biodegradable PBS.
\end{abstract}

Keywords: polyamide 11; poly(butylene succinate); polymer blends; bio-based polymers; biodegradable polymers; mechanical properties; thermal analysis; morphology; spectroscopy

\section{Introduction}

Nowadays, synthetic polymers have replaced many traditional materials, such as wood, stone, metal, and ceramics, and they are used in all areas of daily life and application: they protect food and prevent spoilage, insulate electric cables, save fuel by making cars lighter and safer, are used as fabric for clothing, in contact lenses, etc. Out of about the 335 million tons of plastics produced annually, $99 \%$ are produced from petroleum [1], and it is expected that, by 2050, the plastics industry will account for $20 \%$ of the total oil consumed annually [2]. Such large use of synthetic polymers resulted in increasing environmental concern, which, coupled to the realization that petroleum resources are finite, led to considerable search for alternative sources of raw materials for the production of new polymers. Moving away from petrochemical feedstocks toward short-term renewable resources will moderate the detrimental influence of plastics on the environment. It is expected that the polymers that are produced from short-term, e.g., annually renewable feedstocks, which are often addressed as bio-based polymers, might fully replace those produced from fossil sources [3].

At present, several bio-based polymers are industrially produced, with applications that mainly include food packaging and agriculture, as well as biomedical devices [4-6]. Properties and the performance/cost ratio of bio-based polymers need to be improved in order to expand the variety of potential fields and enter new markets. A popular route applied for decades, also for classical polymers, is to tailor the properties of a given polymer for specific applications by blending [7-9]. 
This approach of enhancing properties is relatively inexpensive in comparison to developing new polymerization routes to attain novel polymers. In other words, research and development of new polymer blends play a crucial role in increasing the competitiveness of bio-based polymers.

One of the most important bio-based polymers is polyamide 11 (PA 11), which is a commercial aliphatic polyamide that is produced from castor oil $[2,10,11]$. Even if only representing a small fraction of the worldwide polyamide production, PA 11 finds applications in a wide range of fields, thanks to its biocompatibility, good oil and salt water resistance, excellent piezoelectric and cryogenic properties, and lower hydrophilicity as compared to the more widely used polyamides 6 and 6.6 [11,12]. Therefore, PA11 is used as an engineering polymer in a large range of industries, including automotive, offshore applications, as well as food packaging [13,14].

Many research efforts have been devoted to improve the properties of PA 11, mainly through incorporation of inorganic fillers [12-18], or by blending with other, especially bio-based polymers, like poly(L-lactic acid), or polyhydroxyalcanoates to further expand the application range $[19,20]$. Among the various bio-based polymers, blends of PA 11 with poly(butylene succinate) (PBS) have barely been investigated. To our knowledge, only a single study about PA 11/PBS blends was performed, where a composition-dependent improvement of the impact strength of PA 11 was reported, without affecting other mechanical properties, like the flexural modulus [21]. From these results, it appears that the addition of PBS has potential to improve properties of PA 11, also taking into account that PBS is not only bio-based, but also biodegradable and compostable [22,23], contrarily to PA 11. In addition, the production of PBS only requires half the costs as the production of an equivalent amount of PA 11 [24-26]. Therefore, PA 11/PBS blends appear as promising new polymeric materials, with reduced material/production costs as compared to plain PA 11, and expected to be also partially biodegradable.

The biodegradation of PBS chains is initiated by the hydrolysis of ester bonds, which leads to the formation of water-soluble fragments with a molar mass lower than $500 \mathrm{Da}$. These short PBS chain segments can be assimilated by microorganisms, and then turned to carbon dioxide, water, and biomass [22,23]. Conversely, PA 11 is not easily decomposable in the environment. Hence, PA 11 formulations containing PBS may be partially biodegradable, with the extent of biodegradation of these blends currently under investigation.

PA 11 and PBS are both semi-crystalline polymers. PA 11 is rigid at room temperature, with a glass transition temperature of the mobile amorphous fraction (MAF) of $T_{\mathrm{g}}=43^{\circ} \mathrm{C}$ [27], and a rigid amorphous fraction (RAF) that devitrifies at higher temperatures [28]. It also exhibits crystal polymorphism that depends on thermo-mechanical history, with six different crystal modifications being reported in the literature [29-32]. After melt processing, like injection-molding [33], the polymer is semi-crystalline at room temperature, often containing lamellar crystals, which were grown to form a spherulitic superstructure. The maximum crystal fraction, similar as in case of other linear polyamides, is well below $50 \%$, however, contributing to its balanced property profile [27]. Further dedicated studies about semi-crystalline morphologies of PA 11 forming, e.g., at high supercooling of the melt, or developed upon self-nucleation are available in the literature [34,35]. At room temperature, PBS has a rubbery mobile amorphous fraction, with a glass transition below $-30{ }^{\circ} \mathrm{C}$ [36], as well as sizable RAF, whose vitrification/devitrification was quantified in [37] as a function of the cooling rate. In addition, the melting points of the two polymers largely differ, with the equilibrium melting temperature $\left(T_{m}^{o}\right)$ of PBS in the range of $127.5-146.5^{\circ} \mathrm{C}$ [38], whereas PA 11 has a $T_{m}^{o}=203-220^{\circ} \mathrm{C}[39,40]$.

PBS is already used as additive in other bio-based polymer formulations, for instance, in blends with poly(lactic acid) (PLA), to improve the flexibility, toughness, and heat resistance of PLA [41], and it is likely that the addition of PBS also has potential for improving properties of PA 11. As mentioned above, PBS may improve the impact strength of PA 11 while maintaining the flexural modulus, as recently published in a short communication [21]. However, information regarding these blends are limited to quantitative data on impact strength and modulus, supported by analysis of morphology of the blends [21]. The improvement of mechanical properties of PA 11 upon the addition of PBS, as probed in [21], deserves a more detailed investigation, to fully exploit the potential of these blends 
and optimize both composition and processing. For these reasons, a detailed investigation of the influence of PBS on the thermal and mechanical properties of PA 11 is needed, which is reported in this manuscript for blends containing the polyamide as the main component. This will be completed by a thorough analysis of the influence of thermal history on the crystallization kinetics of both polymers, to be presented in a forthcoming manuscript.

\section{Experimental Part}

\subsection{Materials}

A heat- and light-stabilized PA 11, extrusion grade Rilsan ${ }^{\circledR}$ BESNO TL from Arkema (Colombes, France), was used. The melt volume index of the polymer is $1 \mathrm{~cm}^{3} / 10 \mathrm{~min}\left(235^{\circ} \mathrm{C}\right.$, $2.16 \mathrm{~kg}$ ) [42] and the number-average molar mass and polydispersity are $17.2 \mathrm{~kg} \mathrm{~mol}^{-1}$ and around 2, respectively [35]. Further material data are available at the Arkema website [42].

PBS Bionolle 1001MD was kindly received by Showa Denko K. K. (Japan). This polymer grade has a melt-flow index of $1.4 \mathrm{~g} / 10 \mathrm{~min}\left(190^{\circ} \mathrm{C}, 2.16 \mathrm{~kg}\right)$. The number-average molar mass and polydispersity are $57.7 \mathrm{~kg} \mathrm{~mol}^{-1}$ and 2, respectively, as measured by gel permeation chromatography.

Before melt mixing, the PA 11 and PBS pellets were dried in a vacuum oven at $80{ }^{\circ} \mathrm{C}$ for $4 \mathrm{~h}$, or $60^{\circ} \mathrm{C}$ for $16 \mathrm{~h}$, respectively.

\subsection{Blend Preparation}

Binary PA 11/PBS blends with a composition of 100/0, 90/10, 80/20, 60/40 m/m\% were prepared by melt mixing in a Brabender-like apparatus Rheocord EC of Haake Inc. (Vreden, Germany) at $210^{\circ} \mathrm{C}$ and $32 \mathrm{rpm}$ for $8 \mathrm{~min}$.

\subsection{Preparation of Compression-Molded Sheets}

PA 11/PBS blends were compression-molded with a Collin Hydraulic Laboratory Forming Press P $200 \mathrm{E}$. The blends were heated to $210^{\circ} \mathrm{C}$ and then kept at this temperature for $2 \mathrm{~min}$ without application of any pressure, to allow for complete melting. After this period, a load of 0.5 tons was applied for $2 \mathrm{~min}$, and then the sample was cooled to room temperature in less than $3 \mathrm{~min}$ by means of cold water circulating in the plates of the press. Compression-molded sheets with a thickness of about $300 \mu \mathrm{m}$ were obtained. A compression-molded sheet of plain PBS was also prepared, by pre-melting at $135^{\circ} \mathrm{C}$ for $2 \mathrm{~min}$, followed by molding with a load of 0.5 ton for $2 \mathrm{~min}$, and then cooling to room temperature via cold water circulating in the plates of the press. A lower molding temperature was used to attain sheets with the same thickness as the PA11/PBS blends. However, the varied thermal history did not lead to significant variation in the analyzed material properties, which were limited to thermal stability (thermal degradation of PBS initiates above $300^{\circ} \mathrm{C}$, as shown below), glass transition, and crystallization/melting behavior (the cooling rate from the relaxed melt was the same as the blends), nor affected infrared spectroscopy analysis.

\subsection{Differential Scanning Calorimetry}

Differential scanning calorimetry (DSC) was performed with a Perkin-Elmer Pyris Diamond DSC (Waltham, MA, USA) that was equipped with an Intracooler II as cooling system. The instrument was calibrated in temperature and energy with a high purity indium standard, using dry nitrogen as purge gas at a flow rate of $30 \mathrm{~mL} \mathrm{~min}^{-1}$. The compression-molded blends were analyzed upon heating at $20 \mathrm{~K} \mathrm{~min}^{-1}$, from -60 to $210^{\circ} \mathrm{C}$. The molded samples had a thickness of $300 \mu \mathrm{m}$, which corresponds to about $6 \mathrm{mg}$ when cut to fit into DSC sample pans. The experimentally measured heat-flow-rate raw data were corrected for instrumental asymmetry by subtraction of a baseline, measured under identical conditions as the samples, including a close match of the masses of the aluminum pans. All of the experiments were repeated three times to ensure reproducibility. 


\subsection{Thermogravimetry}

Thermogravimetric analyses (TGA) were carried out with a Perkin Elmer Pyris Diamond TG-DTA instrument under nitrogen atmosphere. Measurements were performed on samples of about $5 \mathrm{mg}$, and then heated from room temperature to $600{ }^{\circ} \mathrm{C}$ at $10 \mathrm{~K} \mathrm{~min}^{-1}$ in nitrogen atmosphere, with a nominal gas flow rate of $30 \mathrm{~mL} \mathrm{~min}^{-1}$.

\subsection{Fourier-Transform Infrared Spectroscopy}

Fourier-transform infrared spectroscopy (FTIR) spectroscopy was performed in reflection mode while using a PerkinElmer FTIR Spectrometer Model Spectrum 100 equipped with a PerkinElmer Universal Attenuated Total Reflectance (ATR) sampling accessory with a diamond crystal. Each spectrum is an average of 16 individual scans, recorded at a resolution of $2 \mathrm{~cm}^{-1}$. The compression-molded blends were analyzed by directly placing the films on the diamond crystal. Each spectrum was repeated three times.

\subsection{Scanning Electron Microscopy}

Morphological analysis of cryogenically fractured PA 11/PBS blends was performed while using a FEI Quanta 200 FEG environmental scanning electron microscope (ESEM) (Eindhoven, The Netherlands) in low vacuum mode, while using a Large Field Detector (LFD) and an accelerating voltage of $30 \mathrm{kV}$. Before analysis, the samples were sputtered-coated with an Au-Pd alloy using a Baltech Med 020 Sputter Coater System and mounted on aluminum stubs by means of carbon adhesive disks.

\subsection{Tensile Tests}

Dumbbell-shaped specimens with a length and thickness of the gauge section of 25 and $4 \mathrm{~mm}$, respectively, were cut from the compression molded sheets and then used for tensile measurements. Stress-strain curves were obtained with an Instron machine, Model 4505 (Norwood, MA, USA) at a cross-head speed of $5 \mathrm{~mm} \mathrm{~min}^{-1}$. Young's modulus, stress, and strain at yield and at break were calculated from an average of seven specimens.

\section{Results and Initial Discussion}

Figure 1 illustrates the apparent specific heat capacity $\left(c_{\mathrm{p}}\right)$ plots of PA 11/PBS compression-molded sheets, as measured upon heating at $20 \mathrm{~K} \mathrm{~min}^{-1}$, one day after preparation. Plain PA 11 (black curve) displays a glass transition temperature $\left(T_{\mathrm{g}}\right)$ centered at $41{ }^{\circ} \mathrm{C}$, as typical for PA 11 [27,39], with the corresponding heat-capacity increment overlapping with a small enthalpy-recovery peak that is caused by the short storage at room temperature (i.e., below $T_{\mathrm{g}}$ ), as well as by the different cooling/heating rates used [43]. The material shows double melting due to crystal reorganization on slow heating, which is in agreement with literature data [27]; the final melting peak is detected at $188^{\circ} \mathrm{C}$.

The DSC plot of plain PBS (magenta curve) shows a $T_{\mathrm{g}}$ of $-36^{\circ} \mathrm{C}$, with a $c_{\mathrm{p}}$-jump that points to a mobile amorphous content of $w_{\mathrm{A}}=0.22$, as calculated by comparison the measured $c_{\mathrm{p}}$-step to the heat capacity step at $T_{\mathrm{g}}$ of the fully amorphous polymer [37,44]. This is followed by a small endotherm peaked at $42{ }^{\circ} \mathrm{C}$, coupled with a sizable increase of $c_{\mathrm{p}}$, and then by a broad endotherm, a sharp recrystallization, and a final melting peak. The overall crystal fraction, as measured by a comparison of the experimentally observed enthalpy of fusion and the heat of fusion of $100 \%$ crystalline PBS of $220 \mathrm{~J} \mathrm{~g}^{-1}$ [45] indicates a crystal fraction $w_{\mathrm{C}}=0.28$. The rigid amorphous fraction, $w_{\mathrm{RA}}$, as calculated by difference [46-48], amounts to $w_{\mathrm{RA}}=0.50$. Small endotherms at temperatures close to $40{ }^{\circ} \mathrm{C}$ have been reported in the literature for PBS, and ascribed to the melting of small crystals that is caused by annealing at temperatures above $T_{\mathrm{g}}$ [45]. However, the integration of the endotherm peaked at $42{ }^{\circ} \mathrm{C}$ in Figure 1 leads to a small enthalpy of transition that may be linked to melting of only $1 \%$ of PBS crystals, a too low amount to justify the marked increase in $c_{p}$, which instead reveals the mobilization of 0.35 of 
solid fraction. It may be speculated that the endotherm at $42{ }^{\circ} \mathrm{C}$ is linked to enthalpy relaxation of the RAF, which partly mobilizes in this temperature range [37].

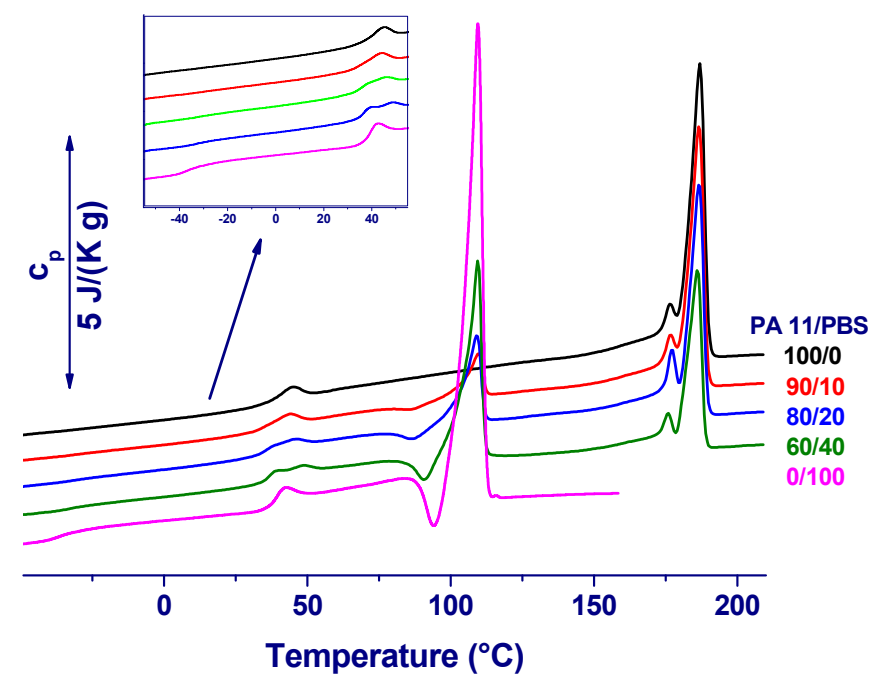

Figure 1. Apparent specific heat capacity $\left(c_{\mathrm{p}}\right)$ of compression-molded PA 11/PBS sheets as a function of temperature, measured upon heating at $20 \mathrm{~K} \mathrm{~min}^{-1}$. Data are shifted vertically for clarity.

The DSC plots of PA 11/PBS blends containing between 10 and $40 \mathrm{~m} \%$ PBS display multiple thermal events, which are close to the algebraic sum of the $c_{\mathrm{p}}$ curves of the two polymers. The glass transition of PBS, centered at $-36{ }^{\circ} \mathrm{C}[36,49]$, is hardly detectable in the 90/10 blend, but it becomes more intense with the increasing content of PBS in the blend, as seen in the insert of Figure $1 . T_{\mathrm{g}}$ of PA 11 overlaps with the small endotherm peaked at $42{ }^{\circ} \mathrm{C}$ in plain PBS, with the latter intensifying with a higher PBS content. When compared to neat polymers, the melting of PA 11 crystals in the blends seems scaling in size with composition, whereas the recrystallization and melting of PBS crystals in the blends also display a small shift in temperature. The detection of two separate $T_{\mathrm{g}}$ 's in the blends, occurring at the same temperatures as in the plain polymers, indicates the immiscibility of PA 11 and PBS. This is confirmed by the occurrence of separate crystallization and melting events of the two polymers, but with some influence of PA 11 on crystallization and melting of PBS chains.

The crystal fractions of PA 11 and PBS in the blends were determined by the integration of the melting endotherms and normalization to the content of the respective blend component. The measured melting enthalpy of PA 11 fraction is $40 \pm 1 \mathrm{~J} \mathrm{~g}^{-1}$, independent of the blend composition. PA 11 is a polymorphic polymer and it exhibits six different crystalline phases [29-31]. The melting profile of PA 11 that is shown in Figure 1 indicates presence of the $\alpha$-modification, as it is expected for the selected pathway of preparation [27]. Literature data on the bulk enthalpy of melting of PA $11 \alpha$-crystals vary from 189 to $244 \mathrm{~J} \mathrm{~g}^{-1}$ [27], which leads to a crystal fraction of the PA 11 part ( $w_{\mathrm{C}, \mathrm{PA}}$ ) of 0.16 to 0.21 , respectively. Additionally, the heat of fusion of the PBS fraction, normalized to its content in the blends, seems to be unaffected by the blend composition, and it amounts to $55 \pm 0.5 \mathrm{~J} \mathrm{~g}^{-1}$. A comparison of the measured heat of fusion with the heat of fusion of $100 \%$ crystalline PBS of $220 \mathrm{~J} \mathrm{~g}^{-1}$ [45] results in a crystal fraction of the PBS parts in the blends $\left(w_{\mathrm{C}, \mathrm{PBS}}\right)$ of 0.26 . As such, the total crystal fraction $\left(w_{\mathrm{C}}=w_{\mathrm{C}, \mathrm{PA}}+w_{\mathrm{C}, \mathrm{PBS}}\right)$ of the compression molded sheets linearly increases with the addition of PBS, due to its larger crystallinity, from $16 \%$ in plain PA 11 to $20 \%$ in the PA 11/PBS blend 60/40.

To gain information about the phase structure and morphology of PA 11/PBS blends, scanning electron microscopy (SEM) analyses were performed, with the results presented in Figure 2. Figure 2a illustrates the cryogenically-fractured surfaces of compression-molded, plain PA 11, which appears smooth, as expected. The addition of PBS (Figure $2 b-d$ ) results in formation of a matrix-particle structure, that is, there occurred phase separation. The size of the particles increases with PBS content in the blends, which, coupled to the small voids surrounding the minor phase inclusions, seems to suggest 
a scarce interfacial adhesion. Otherwise, the PBS particles appear homogeneously distributed within the matrix, and most of them were not pulled out during the cryogenical fracture process, rather than remained attached to the matrix, perhaps indicating compatibility between the blend components.

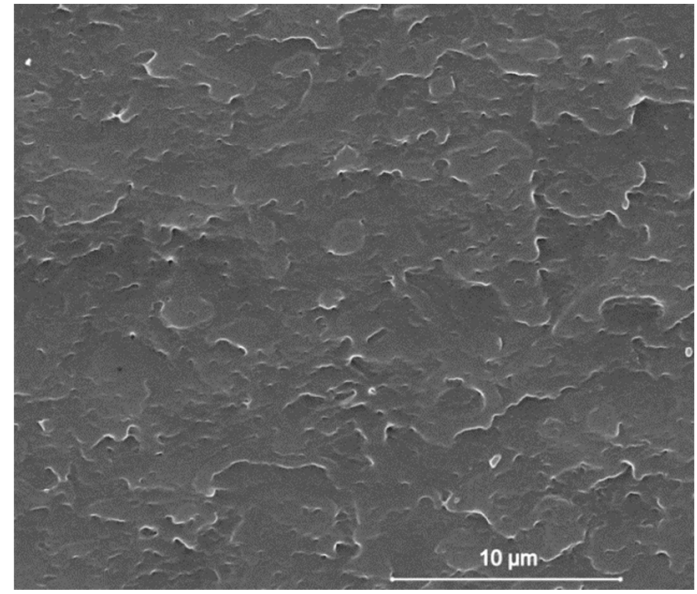

(a)

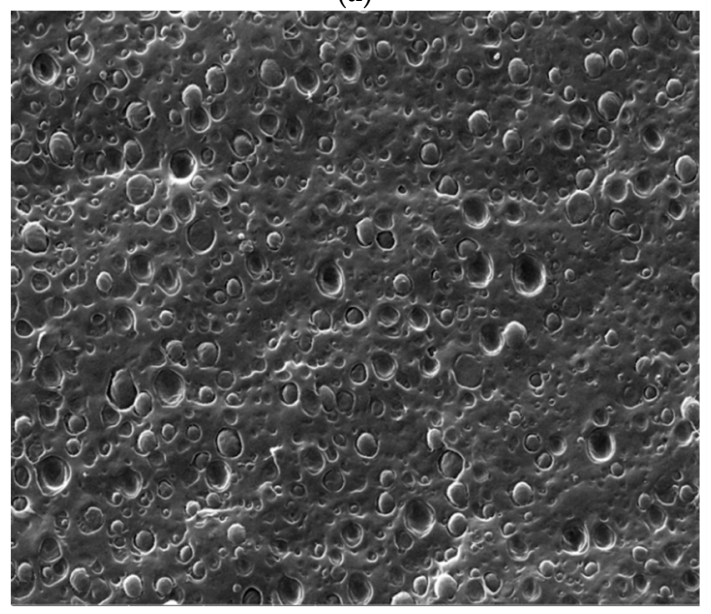

(c)

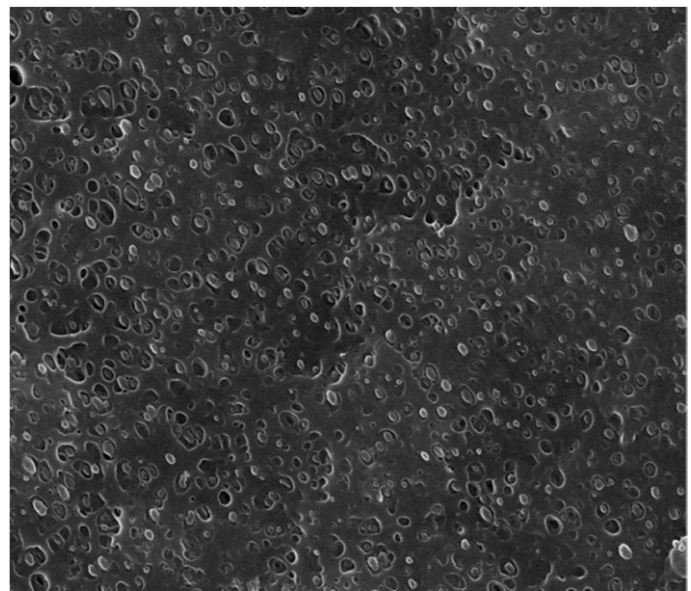

(b)

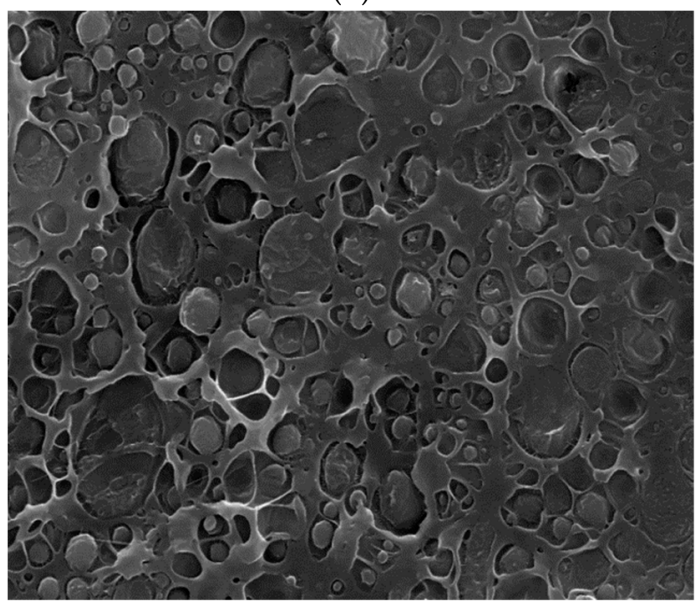

(d)

Figure 2. Scanning electron micrographs of cryogenically fractured surfaces of PA 11/PBS blends: (a) 100/0; (b) 90/10; (c) 80/20; and, (d) 60/40.

Close inspection of the cryogenically fractured surfaces revealed the presence of small fibrils between the dispersed PBS particles and the PA 11 matrix. This is illustrated in Figure 3, which shows the morphology of the cryogenically fractured 60/40 blend at higher magnification. PBS droplets appear to be bonded to PA 11 via small fibrils, which join the two phases, however leaving some voids. Such fibrils are observed in all of the analyzed blends of different composition, and they are also reported in [21]. These fibrils/voids may form during fracture, due to the release of residual/internal stress imposed to the blends by crystallization/volume contraction of the components at different temperatures, by different thermal shrinkage of the PA 11 and PBS, or by cooling-rate gradients during melt-processing [50]. In fact, the fibrils indicate coupling of the matrix and particles, which is perhaps due to interaction between the functional groups of PA 11 and PBS macromolecules, established during melt mixing, which might provide partial compatibilization of the blend components. 


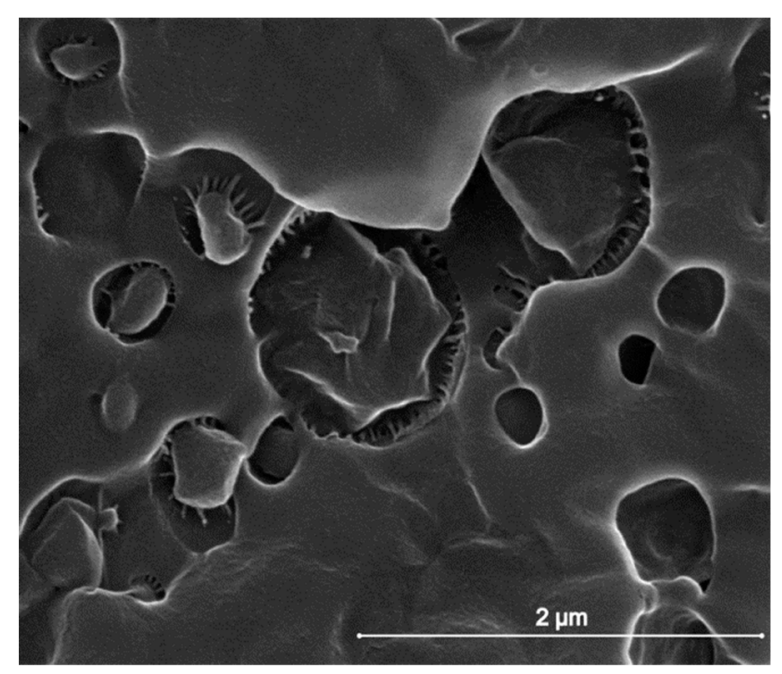

Figure 3. Scanning electron micrograph of a cryogenically fractured surface of the PA 11/PBS 60/40 blend.

The type of interaction was investigated by FTIR-ATR analysis. Figure 4a shows the FTIR-ATR spectra of plain PA 11 (black), plain PBS (magenta), and the 60/40 blend (green) in the wavenumber range from 3500 to $1400 \mathrm{~cm}^{-1}$. The FTIR-ATR spectrum of plain PBS has a complex band at around $1712 \mathrm{~cm}^{-1}$, which is the convolution of three different $\mathrm{C}=\mathrm{O}$ stretching modes at around 1736, 1720, and $1714 \mathrm{~cm}^{-1}$ [51]. The band at $1736 \mathrm{~cm}^{-1}$ corresponds to the stretching mode of $\mathrm{C}=\mathrm{O}$ in the mobile amorphous fraction, the one at $1720 \mathrm{~cm}^{-1}$ is assigned to the stretching in the rigid amorphous fraction and the one at $1714 \mathrm{~cm}^{-1}$ regards the crystalline phase. The FTIR-ATR spectrum of PA 11 has a band at $1635 \mathrm{~cm}^{-1}$ that corresponds to the stretching mode of $\mathrm{C}=\mathrm{O}$, a band at $3300 \mathrm{~cm}^{-1}$ that is assigned to the N-H stretching and the amide II band at $1540 \mathrm{~cm}^{-1}$. This latter band results from an interaction between $\mathrm{N}-\mathrm{H}$ bending and the $\mathrm{C}-\mathrm{N}$ stretching of the $\mathrm{C}-\mathrm{N}-\mathrm{H}$ group.

Focusing on the FTIR-ATR spectra of the blends in the range between 1450 and $1800 \mathrm{~cm}^{-1}$ (Figure $4 \mathrm{~b}$ ), the $\mathrm{C}=\mathrm{O}$ stretching band in plain PBS shows a shift of $3 \mathrm{~cm}^{-1}$ on the addition of $10 \mathrm{~m} \%$ PA 11. At the same time, a shift of the N-H stretching mode band and the amide II band of PA11 is observed. The amide II band progressively shifts from $1540 \mathrm{~cm}^{-1}$ in plain PA 11 to $1544 \mathrm{~cm}^{-1}$ in the $60 / 40$ blend, together with a shift of $2 \mathrm{~cm}^{-1}$ on the $\mathrm{N}-\mathrm{H}$ stretching band at $3300 \mathrm{~cm}^{-1}$, as shown in Figure $4 c$.

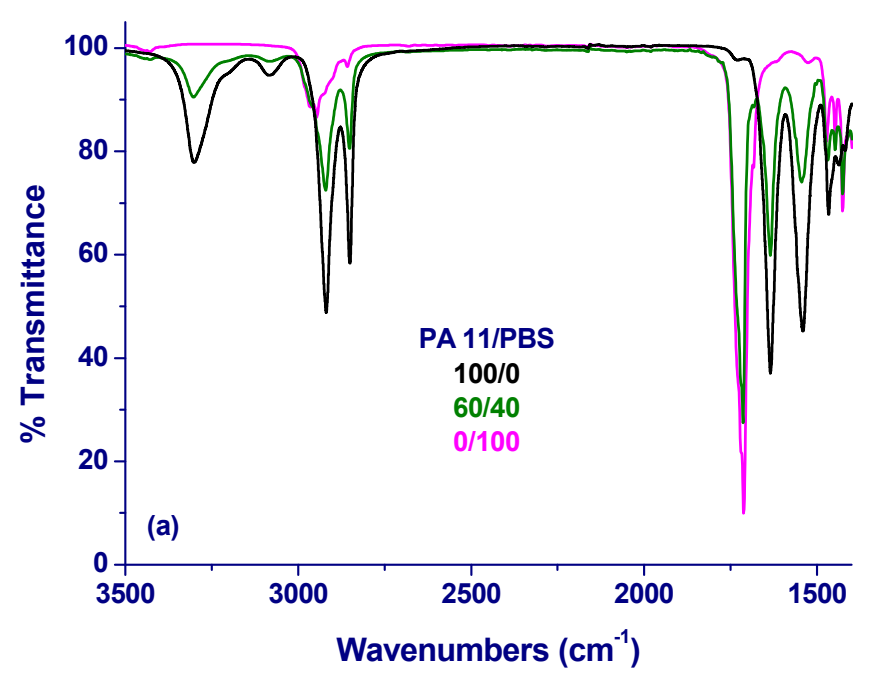

Figure 4. Cont. 

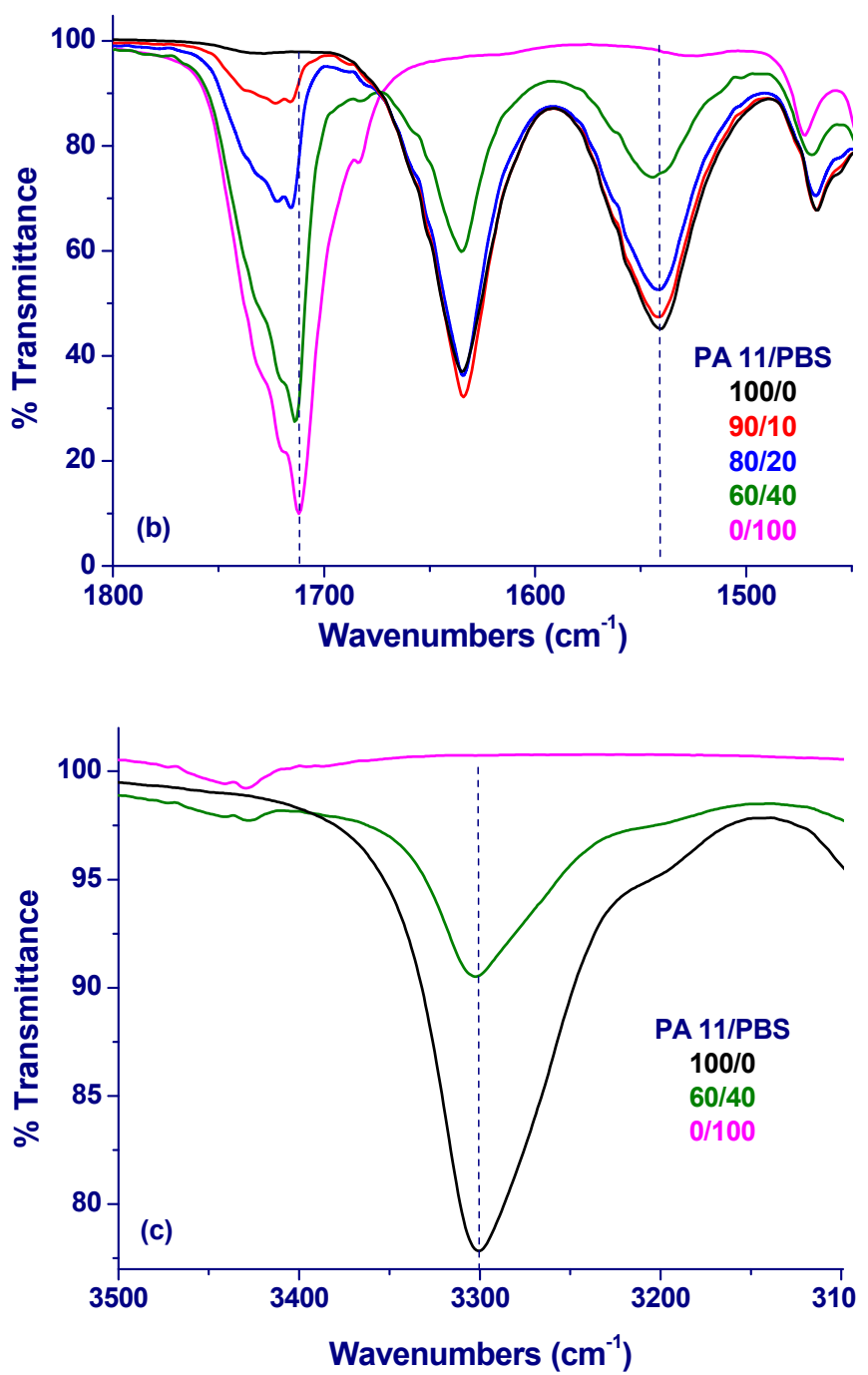

Figure 4. Fourier-transform infrared spectroscopy-Attenuated Total Reflectance (FTIR-ATR) spectra of compression-molded samples of PA 11/PBS blends: (a) plain polymers compared to the 60/40 blend; (b) the whole analyzed composition range, in the wavenumber range from 1800 to $1450 \mathrm{~cm}^{-1}$; and, (c) enlargement of the plots shown in (a) to highlight changes in the wavenumber range of stretching of N-H band of PA 11.

These spectral changes can be rationalized while taking interaction between the carbonyl group of PBS and the N-H group of the amide in PA 11, established upon melt mixing, into account. Even if the shifts are low in terms of frequencies, those are reproducible, hence not are connected to instrumental errors. With the available experimental data, such small variations in wavenumbers can only be ascribed to hydrogen bonding, while also taking into account that the shift of the $\mathrm{C}=\mathrm{O}$ stretching band of PBS is too low to be explained with a change in the crystalline structure of the polymer. However, the latter was shown not to vary by DSC analyses of Figure 1.

The nominal stress-strain curves of PA 11 and PA 11/PBS blends that were obtained at room temperature are presented in Figure 5. Table 1 summarizes the Young's modulus (E), yield stress and strain, and stress and strain at break. All of the analyzed materials show ductile behavior. The deformation of plain polyamide occurs in three stages, as typical for semi-crystalline polymers [52-54]: a first stage, where the stress sharply increases with strain, followed by a homogeneous plastic deformation stage, then a necking phenomenon occurs, which shows that the deformation becomes heterogeneous, until the sample breaks. Plain PA 11 displays a Young's modulus of $E=930 \mathrm{MPa}$, yielding occurs at strain $\varepsilon_{\mathrm{y}}=25 \%$, and stress $\sigma_{\mathrm{y}}=29 \mathrm{MPa}$, and rupture at 
elongation $\varepsilon_{\mathrm{r}}=300 \%$, and stress $\sigma_{\mathrm{r}}=52 \mathrm{MPa}$. The measured parameters are in line with literature data $[15,55,56]$. The addition of PBS results in a small variation of the measured mechanical parameters, with a small progressive decrease of the Young's modulus with the addition of PBS, as well as of the yielding and break parameters.

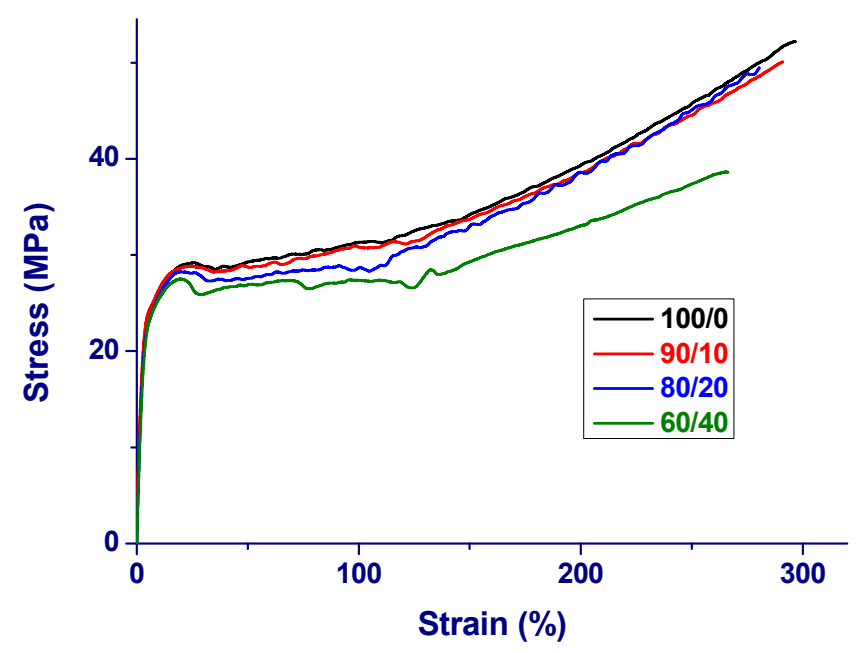

Figure 5. Engineering tensile stress-strain plot of PA 11/PBS blends, measured at room temperature, with a crosshead speed $5 \mathrm{~mm} \mathrm{~min}^{-1}$.

Table 1. Tensile parameters of PA 11/PBS blends.

\begin{tabular}{cccccc}
\hline PA 11/PBS & E $\mathbf{( M P a )}$ & $\boldsymbol{\sigma}_{\mathbf{y}} \mathbf{( M P a )}$ & $\varepsilon_{\mathbf{y}} \mathbf{( \% )}$ & $\left.\boldsymbol{\sigma}_{\mathbf{r}} \mathbf{( M P a}\right)$ & $\mathcal{E}_{\mathbf{r}}(\mathbf{\%})$ \\
\hline $100 / 0$ & $930 \pm 40$ & $29 \pm 1$ & $25 \pm 2$ & $52 \pm 3$ & $300 \pm 20$ \\
$90 / 10$ & $910 \pm 30$ & $29 \pm 1$ & $25 \pm 3$ & $50 \pm 3$ & $290 \pm 20$ \\
$80 / 20$ & $890 \pm 40$ & $28 \pm 2$ & $23 \pm 5$ & $49 \pm 5$ & $280 \pm 20$ \\
$60 / 40$ & $870 \pm 30$ & $27 \pm 2$ & $20 \pm 3$ & $39 \pm 5$ & $270 \pm 30$ \\
\hline
\end{tabular}

Literature data of Young's modulus of plain PBS range from 500 to $590 \mathrm{MPa}[57,58]$, i.e., the modulus is lower than in PA 11. PBS is more ductile than PA 11, with $\varepsilon_{\mathrm{r}}=950 \%$ [59], although some authors also reported PBS as being a brittle polymer [60,61], probably due to material degradation [62]. All of the analyzed PA 11/PBS blends display ductile behavior, exhibiting elongation values that resemble those of the plain polyamide.

It is well known that in semi-crystalline polymers Young's modulus increases with the crystal fraction [63-65]. The slight decrease of Young's modulus in the blends is caused by the lower modulus of PBS, which overwhelms the somewhat higher overall crystallinity of the material. Being measured at low strain, Young's modulus is not significantly affected by the blend morphology, whereas large-strain properties, like stress and strain at break, strongly depend on the morphology, including phase separation in the amorphous phase, as well as the homogeneity of dispersion and adhesion between the phases. Good tensile properties, such as tensile strength and yield and ultimate parameters, can be expected if the domains are small in size and well dispersed in the surrounding matrix [66]. As seen in Figure 2, the PA 11/PBS blends present an island-matrix morphology with PBS particles surrounded by small voids, and with a particle size that varies with blend composition. However, the PBS particles are not decoupled from the matrix, but are kept connected with fibrils, which is probably due to interaction between the amide and carbonyl groups of the two polymers, as suggested by FTIR-ATR analysis. Such fibrils that bridge the PA 11 and PBS phases allow the samples to bear high elongation, comparable to that of pure PA 11, with a small decrease only observed in the blend containing $40 \mathrm{~m} \%$ of the dispersed component. 
The influence of PBS on the thermal stability of PA 11 was investigated by thermogravimetry (TGA). The TGA plot of PA 11/PBS blends, analyzed upon heating at $10 \mathrm{~K} \mathrm{~min}^{-1}$ in nitrogen atmosphere, is presented in Figure 6a, while the derivative thermogravimetry curves are shown in Figure 6b. The TGA curve of plain polyamide displays a slow mass loss between 200 and $380{ }^{\circ} \mathrm{C}$, with an overall mass decrease of about $5 \%$. A further increase of the temperature leads to a steep decrease of the polymer mass, with full decomposition of the polymer just below $500{ }^{\circ} \mathrm{C}$ [25], and a maximum degradation rate being observed at $455^{\circ} \mathrm{C}$, as seen in Figure $6 \mathrm{~b}$. Pure PBS also undergoes thermal degradation in a single step, with no significant mass loss until about $300{ }^{\circ} \mathrm{C}$ and complete decomposition around $430{ }^{\circ} \mathrm{C}$, which is in agreement with the literature data $[67,68]$. The primary mass loss is caused by the volatilization of small molecules, including succinic acid and butylene glycol, followed by major thermal degradation of PBS chains, due to random chain scission at the ester bonds, with the formation of carboxylic end groups and vinyl groups [38].

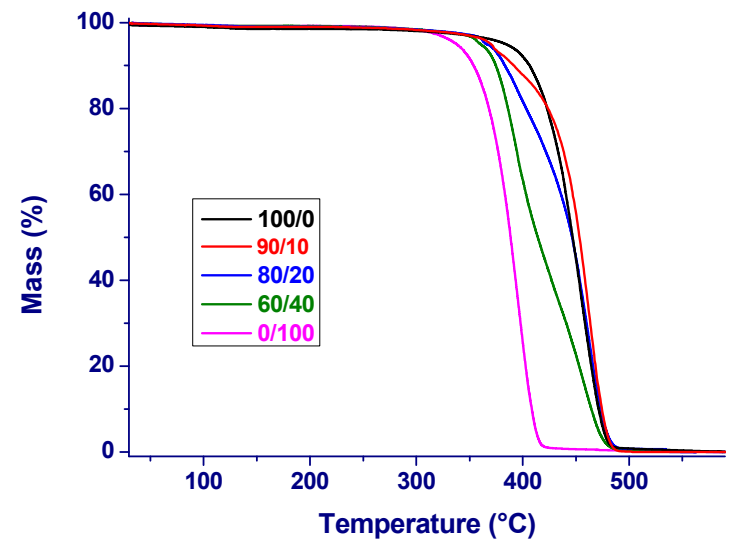

(a)

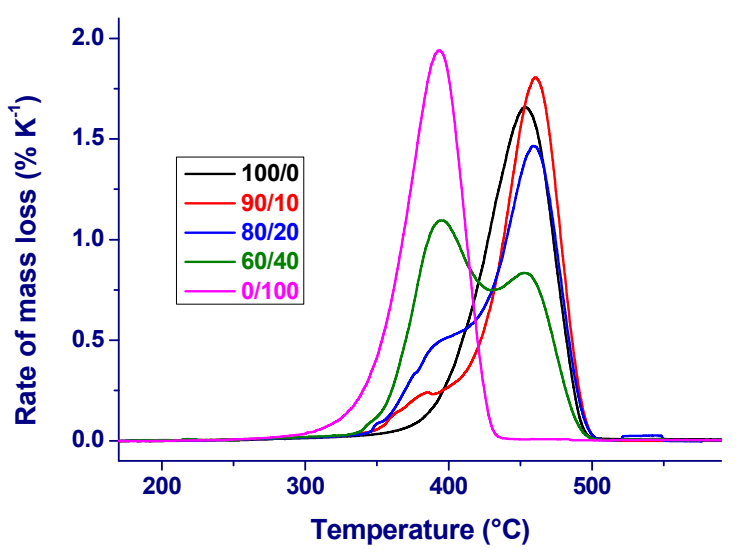

(b)

Figure 6. Thermogravimetry (TGA) plots of PA 11/PBS blends, measured in nitrogen atmosphere upon heating at $10 \mathrm{~K} \mathrm{~min}^{-1}$ : (a) normalized mass as function of temperature; and, (b) rate of mass loss as function of temperature.

In the blends, thermal degradation is initiated at the same temperature as the degradation of plain PBS, with all of the analyzed compositions displaying two major steps of mass loss, mostly resembling those of the pure components. The peaks in the degradation rate of the PBS particles of the blends appear unchanged as compared to the pure polymer, with a minor shift of the degradation of the PA 11 portions of the blends, which undergo degradation at slightly higher temperatures. This suggests some minor influence of the degradation products of PBS on the thermal degradation of PA 11.

\section{Final Discussion and Conclusions}

Previous research indicated that PBS can be used to improve mechanical properties of PA 11, specifically the impact strength. These data are now completed by a full analysis of the blend morphology, the phase structure, thermal, and tensile properties of PA 11/PBS blends, with PA 11 as major component.

In the analyzed composition range from 0 to $40 \mathrm{~m} \%$ PBS, PA 11 and PBS are immiscible and form a four-phase morphology made of two crystal phases, plus two amorphous phases. The components arrange in a particle-matrix morphology, with roughly spherical PBS particles that are suspended in the PA 11 matrix and small voids surrounding the minority-phase inclusions. Increasing the PBS content from 10 to $40 \mathrm{~m} \%$ results in an increase of the average particle size. Despite the immiscibility of the blend components, the matrix and particles display interfacial adhesion, as most PBS particles are not removed upon cryogenical fracture, but they remain anchored to the matrix. Interaction between the amide groups of PA 11 chains and the carbonyl groups of PBS was proven by FTIR-ATR analysis, 
which may rationalize the adhesion between the phases. This is revealed also by the SEM micrographs of the fractured surfaces of the blend that display small fibrils that bridge the PBS inclusions with the PA 11 matrix.

It may be advisable, and the subject of further investigation, to investigate the effect of addition of a compatibilizer that may further improve the interfacial adhesion between the phases. At the level of compatibility that is only attained by melt blending PA 11 and PBS, the PA 11-rich binary blends display mechanical properties that are comparable to neat PA 11. There is only observed minor variation of the Young's modulus and of the yielding and break parameters, despite that PBS alone can sustain much higher elongation, up to $900 \%$ of the initial value, when compared to the $300 \%$ typical of PA 11 and of the analyzed blends. In other words, it is likely that further increase of interfacial adhesion, which may be provided by a compatibilizer, or by further promoting reaction between the functional groups of the two polymers, might lead to a blend formulation with improved mechanical properties as compared to pure PA 11, and that is also partially biodegradable.

The analysis of the thermal properties indicated little influence of the blend composition on thermal degradation, with only a minor shift of the degradation temperature of the PA 11 matrix upon the addition of PBS. The amorphous phases have separate glass transitions whose temperature seems not be affected by blending, at least for the analyzed composition range. Blending seems not to influence the crystallization of PBS and PA 11, which might appear in contrast with the reported interaction between PA 11 and PBS phases. However, the data that are presented in this manuscript are limited to the processing history imparted upon melt-mixing using a specific extruder and compression molding. The condition of crystallization of PA 11 can influence crystallization kinetics of PBS parts of the blends, which may help in modulating the crystallinity and crystal morphology, and, in turn, material properties, as will be detained in a forthcoming manuscript that illustrates a thorough analysis of crystallization kinetics of both polymers in the blends.

Author Contributions: Conceptualization, M.L.D.L.; methodology, M.L.D.L., A.L. and R.A.; data curation, M.L.D.L. and A.L.; writing—original draft preparation, M.L.D.L.; writing—review and editing, M.L.D.L., A.L. and R.A.; supervision, M.L.D.L.

Funding: This research received no external funding.

Acknowledgments: The authors wish to thank Salvatore Mallardo, Barbara Immirzi, and Maria Cristina Del Barone of IPCB-CNR for their assistance with blend preparation, GPC and SEM analysis, respectively. The authors gratefully acknowledge Showa Denko K. K. (Japan), and Ines Kühnert of Leibniz-Institut für Polymerforschung e.V. Dresden (Germany) for kindly providing PBS and PA 11, respectively.

Conflicts of Interest: The authors declare no conflict of interest.

\section{References}

1. Bioplastic Market Data. Available online: www.european-bioplastics.org/market/ (accessed on 30 May 2019).

2. Scott, J.L.; Buchard, A. Polymers from plants: Biomass fixed carbon dioxide as a resource. In Managing Global Warming-An Interface of Technology and Human Issues; Letcher, T.M., Ed.; Academic Press: Cambridge, MA, USA, 2019; pp. 503-525.

3. Imre, B.; Pukánszky, B. Compatibilization in bio-based and biodegradable polymer blends. Eur. Polym. J. 2013, 49, 1215-1233. [CrossRef]

4. Di Lorenzo, M.L.; Raimo, M.; Cascone, E.; Martuscelli, E. Poly(3-hydroxybutyrate)-based copolymers and blends: Influence of a second component on crystallization and thermal behavior. J. Macromol. Sci.-Phys. 2001, 40, 639-667. [CrossRef]

5. Nakajima, H.; Dijkstra, P.; Loos, K. The Recent Developments in Biobased Polymers toward General and Engineering Applications: Polymers That Are Upgraded from Biodegradable Polymers, Analogous to Petroleum-Derived Polymers, and Newly Developed. Polymers 2017, 9, 523. [CrossRef] [PubMed]

6. Di Lorenzo, M.L.; Androsch, R. (Eds.) Industrial Applications of Poly(lactic acid); Springer International Publishing: Cham, Switzerland, 2018; p. 282.

7. Paul, D.R.; Newman, S. Polymer Blends; Academic Press: New York, NY, USA, 1978. 
8. Sionkowska, A. Current research on the blends of natural and synthetic polymers as new biomaterials: Review. Progr. Polym. Sci. 2011, 36, 1254-1276. [CrossRef]

9. Hamad, K.; Kaseem, M.; Ayyoob, M.; Joo, J.; Deri, F. Polylactic acid blends: The future of green, light and tough. Progr. Polym. Sci. 2018, 85, 83-127. [CrossRef]

10. Martino, L.; Basilissi, L.; Farina, H.; Ortenzi, M.A.; Zini, E.; Di Silvestro, G.; Scandola, M. Bio-based polyamide 11: Synthesis, rheology and solid-state properties of star structures. Eur. Polym. J. 2014, 59, 69-77. [CrossRef]

11. Patel, R.; Ruehle, D.A.; Dorgan, J.R.; Halley, P.; Martin, D. Biorenewable blends of polyamide-11 and polylactide. Polym. Eng. Sci. 2014, 54, 1523-1532. [CrossRef]

12. He, X.; Yang, J.; Zhu, L.; Wang, B.; Sun, G.; Lv, P.; Phang, I.Y.; Liu, T. Morphology and melt rheology of nylon 11/clay nanocomposites. J. Appl. Polym. Sci. 2006, 102, 542-549. [CrossRef]

13. Liu, T.; Lim, K.P.; Tjiu, W.C.; Pramoda, K.P.; Chen, Z.K. Preparation and characterization of nylon 11/organoclay nanocomposites. Polymer 2003, 44, 3529-3535. [CrossRef]

14. Mancic, L.; Osman, R.F.M.; Costa, A.M.L.M.; d'Almeida, J.R.M.; Marinkovic, B.A.; Rizzo, F.C. Thermal and mechanical properties of polyamide 11 based composites reinforced with surface modified titanate nanotubes. Mater. Des. 2015, 83, 459-467. [CrossRef]

15. Sahnoune, M.; Taguet, A.; Otazaghine, B.; Kaci, M.; Lopez-Cuesta, J.M. Effects of functionalized halloysite on morphology and properties of polyamide-11/SEBS-g-MA blends. Eur. Polym. J. 2017, 90, 418-430. [CrossRef]

16. Yu, M.; Zhang, Q.; Fu, Q. Preparation and characterisation of polyamide 11/clay nanocomposites. Chin. J. Polym. Sci. 2004, 22, 43-47.

17. Halim, K.A.A.; Farrell, J.B.; Kennedy, J.E. Preparation and characterisation of polyamide 11/montmorillonite (MMT) nanocomposites for use in angioplasty balloon applications. Mater. Chem. Phys. 2013, 143, 336-348. [CrossRef]

18. Jariyavidyanont, K.; Focke, W.; Androsch, R. Crystallization kinetics of polyamide 11 in presence of sepiolite and montmorillonite nanofillers. Coll. Polym. Sci. 2016, 294, 1143-1151. [CrossRef]

19. Tercjak, A.; Haponiuk, J.T.; Masiulanis, B. Study of thermal property changes of biopol/polyamide 11 blends during biodegradation in compost. J. Therm. Anal. Calor. 2003, 74, 605-608. [CrossRef]

20. Walha, F.; Lamnawar, K.; Maazouz, A.; Jaziri, M. Rheological, Morphological and Mechanical Studies of Sustainably Sourced Polymer Blends Based on Poly(Lactic Acid) and Polyamide 11. Polymers 2016, 8, 61. [CrossRef] [PubMed]

21. Moriyama, T.; Sumiya, N.; Saito, T. Impact strength improvement of polyamide 11 without flexural modulus reduction by dispersing poly(butylene succinate) particles. Polym. J. 2016, 48, 221-224. [CrossRef]

22. Ichikawa, Y.; Mizukoshi, T. Bionolle (Polybutylenesuccinate). Adv. Polym. Sci. 2012, 245, 285-313.

23. Wu, Y.; Xiong, W.; Zhou, H.; Li, H.; Xu, G.; Zhao, J. Biodegradation of poly(butylene succinate) film by compost microorganisms and water soluble product impact on mung beans germination. Polym. Degrad. Stab. 2016, 126, 22-30. [CrossRef]

24. Chanoine, P. Specialty Polyamides High Performance Materials Segment. Available online: https://www.arkema.com/export/sites/global/.content/medias/downloads/investorrelations/en/finance/ arkema-investor-day-2012-specialty-polyamides-va.pdf (accessed on 1 July 2019).

25. Schütte, A. Processing of Bioplastics: A Guideline. Available online: https://www.ifbb-hannover.de/files/ IfBB/downloads/EV_Processing-of-Bioplastics-2016.pdf (accessed on 1 July 2019).

26. Van den Oever, M.; Molenveld, K.; van der Zee, M.; Bos, H. Bio-Based and Biodegradable Plastics: Facts and Figures: Focus on Food Packaging in the Netherlands (Rapport nr. 1722); Wageningen Food Biobased Research: Wageningen, The Netherlands, 2017; ISBN 9789463431217.

27. Jariyavidyanont, K.; Focke, W.; Androsch, R. Thermal Properties of Biobased Polyamide 11. In Advances in Polymer Science; Springer: Berlin/Heidelberg, Germany, 2019.

28. Xenopoulos, A.; Wunderlich, B. Thermodynamic properties of liquid and semicrystalline linear aliphatic polyamides. J. Polym. Sci. Part B Polym. Phys. 1990, 28, 2271-2290. [CrossRef]

29. Mathias, L.J.; Powell, D.G.; Autran, J.P.; Porter, R.S. Nitrogen-15 nmr characterization of multiple crystal forms and phase transitions in polyundecanamide (nylon 11). Macromolecules 1990, 23, 963-967. [CrossRef]

30. Zhang, G.; Li, Y.; Yan, D. Polymorphism in nylon-11/montmorillonite nanocomposite. J. Polym. Sci. Part B Polym. Phys. 2004, 42, 253-259. [CrossRef]

31. Nair, S.S.; Ramesh, C.; Tashiro, K. Crystalline phases in nylon-11: Studies using HTWAXS and HTFTIR. Macromolecules 2006, 39, 2841-2848. [CrossRef] 
32. Rhoades, A.M.; Wonderling, N.; Schick, C.; Androsch, R. Supercooling-controlled heterogeneous and homogenous crystal nucleation of polyamide 11 and its effect onto the crystal/mesophase polymorphism. Polymer 2016, 106, 29-34. [CrossRef]

33. Jariyavidyanont, K.; Williams, J.L.; Rhoades, A.M.; Kühnert, I.; Focke, W.; Androsch, R. Crystallization of polyamide 11 during injection molding. Polym. Eng. Sci. 2018, 58, 1053-1061. [CrossRef]

34. Mollova, A.; Androsch, R.; Mileva, D.; Schick, C.; Benhamida, A. Effect of supercooling on crystallization of polyamide 11. Macromolecules 2013, 46, 828-835. [CrossRef]

35. Jariyavidyanont, K.; Janke, A.; Androsch, R. Crystal self-nucleation of polyamide 11. Thermochim. Acta 2019, 677, 139-143. [CrossRef]

36. Di Lorenzo, M.L.; Androsch, R.; Righetti, M.C. Low-temperature crystallization of poly(butylene succinate). Eur. Polym. J. 2017, 94, 384-391. [CrossRef]

37. Signori, F.; Pelagaggi, M.; Bronco, S.; Righetti, M.C. Amorphous/crystal and polymer/filler interphases in biocomposites from poly(butylene succinate). Thermochim. Acta 2012, 543, 74-81. [CrossRef]

38. Gan, Z.; Abe, H.; Kurokawa, H.; Doi, Y. Solid-state microstructures, thermal properties, and crystallization of biodegradable poly(butylene succinate) (PBS) and its copolyesters. Biomacromolecules 2001, 2, 605-613. [CrossRef]

39. Pyda, M. (Ed.) Nylon 11 (NYLON11) Heat Capacity, Enthalpy, Entropy, Gibbs Energy; Datasheet from "The Advanced THermal Analysis System (ATHAS) Databank-Polymer Thermodynamics"; Springer Materials, Springer-Verlag GmbH: Heidelberg, Germany, 2014.

40. Zhang, Q.; Mo, Z.; Liu, S.; Zhang, H. Influence of annealing on structure of Nylon 11. Macromolecules 2000, 33, 5999-6005. [CrossRef]

41. Verespej, M. NatureWorks Launches Biopolymer Alloys. Plast. Technol. 2012, 4. Available online: https://www.ptonline.com/articles/natureworks-launches-biopolymer-alloys (accessed on 2 July 2019).

42. Rilsan BESNO TL Product Information. Available online: https://www.extremematerials-arkema.com/en/ materials-database/ (accessed on 28 June 2019).

43. Wunderlich, B. Thermal Analysis of Polymeric Materials; Springer: Berlin/Heidelberg, Germany, 2005.

44. Androsch, R.; Wunderlich, B. Scanning Calorimetry. In Macromolecular Engineering; Matyjaszewski, K., Gnanou, Y., Leibler, L., Eds.; Wiley-VCH Verlag GmbH \& Co. KGaA: Weinheim, Germany, 2011; Volume 3 , Chapter 12.

45. Papageorgiou, D.G.; Zhuravlev, E.; Papageorgiou, G.Z.; Bikiaris, D.; Chrissafis, K.; Schick, C. Kinetics of nucleation and crystallization in poly(butylene succinate) nanocomposites. Polymer 2014, 55, 6725-6734. [CrossRef]

46. Righetti, M.C.; Tombari, E.; Di Lorenzo, M.L. Crystalline, mobile amorphous and rigid amorphous fractions in isotactic polystyrene. Eur. Polym. J. 2008, 44, 2659-2667. [CrossRef]

47. Righetti, M.C.; Laus, M.; Di Lorenzo, M.L. Temperature dependence of the rigid amorphous fraction in poly(ethylene terephthalate). Eur. Polym. J. 2014, 58, 60-68. [CrossRef]

48. Di Lorenzo, M.L.; Righetti, M.C. Crystallization-induced formation of rigid amorphous fraction. Polym. Cryst. 2018, 1, e10023. [CrossRef]

49. Papageorgiou, G.Z.; Bikiaris, D.N. Crystallization and melting behavior of three biodegradable poly(alkylene succinates). A comparative study. Polymer 2005, 46, 12081-12092. [CrossRef]

50. Wu, S. Chain structure, phase morphology, and toughness relationships in polymers and blends. Polym. Eng. Sci. 1990, 30, 753-761. [CrossRef]

51. Yao, S.F.; Chen, X.T.; Ye, H.M. Investigation of Structure and Crystallization Behavior of Poly(butylene succinate) by Fourier Transform Infrared Spectroscopy. J. Phys. Chem. B 2017, 121, 9476-9485. [CrossRef]

52. Hong, K.; Rastogi, A.; Strobl, G. A Model Treating Tensile Deformation of Semicrystalline Polymers: Quasi-Static Stress-Strain Relationship and Viscous Stress Determined for a Sample of Polyethylene. Macromolecules 2004, 37, 10165-10173. [CrossRef]

53. Patlazhan, S.; Remond, Y. Structural mechanics of semicrystalline polymers prior to the yield point: A review. J. Mater. Sci. 2012, 47, 6749-6767. [CrossRef]

54. Pawlak, A.; Galeski, A.; Rozanski, A. Cavitation during deformation of semicrystalline polymers. Progr. Polym. Sci. 2014, 39, 921-958. [CrossRef] 
55. Stoclet, G.; Sclavons, M.; Devaux, J. Relations between structure and property of polyamide 11 nanocomposites based on raw clays elaborated by water-assisted extrusion. J. Appl. Polym. Sci. 2013, 127, 4809-4824. [CrossRef]

56. Ruehle, D.A.; Perbix, C.; Castañeda, M.; Dorgan, J.R.; Mittal, V.; Halley, P.; Martin, D. Blends of biorenewable polyamide-11 and polyamide-6,10. Polymer 2013, 54, 6961-6970. [CrossRef]

57. Li, H.; Chang, J.; Cao, A.; Wang, J. In vitro evaluation of biodegradable poly(butylene succinate) as a novel biomaterial. Macromol. Biosci. 2005, 5, 433-440. [CrossRef] [PubMed]

58. Lin, N.; Yu, J.; Chang, P.R.; Li, J.; Huang, J. Poly(butylene succinate)-based biocomposites filled with polysaccharide nanocrystals: Structure and properties. Polym. Compos. 2011, 32, 472-482. [CrossRef]

59. Yun, I.S.; Hwang, S.W.; Shim, J.K.; Seo, K.H. A Study on the Thermal and Mechanical Properties of Poly (Butylene Succinate)/Thermoplastic Starch Binary Blends. Int. J. Prec. Eng. Manuf.-Green Technol. 2016, 3, 289-296. [CrossRef]

60. Totaro, G.; Sisti, L.; Celli, A.; Askanian, H.; Verney, V.; Leroux, F. Poly(butylene succinate) bionanocomposites: A novel bio-organo-modified layered double hydroxide for superior mechanical properties. RSC Adv. 2016, 6, 4780-4791. [CrossRef]

61. Xu, J.; Guo, B.H. Microbial Succinic Acid, Its Polymer Poly(butylene succinate), and Applications. In Plastics from Bacteria; Microbiology Monographs Volume 14; Chen, G.Q., Ed.; Springer: Berlin/Heidelberg, Germany, 2010; Volume 14.

62. Puchalski, M.; Szparaga, G.; Biela, T.; Gutowska, A.; Sztajnowski, S.; Krucínska, I. Molecular and Supramolecular Changes in Polybutylene Succinate (PBS) and Polybutylene Succinate Adipate (PBSA) Copolymer during Degradation in Various Environmental Conditions. Polymers 2018, 10, 251. [CrossRef]

63. Di Lorenzo, M.L.; Righetti, M.C. The three-phase structure of isotactic poly(1-butene). Polymer 2008, 49, 1323-1331. [CrossRef]

64. Mileva, D.; Zia, Q.; Androsch, R. Tensile properties of random copolymers of polypropylene with ethylene and 1-butene: Effect of crystallinity and crystal habit. Polym. Bull. 2010, 65, 623-634. [CrossRef]

65. Glüge, R.; Altenbach, H.; Kolesov, I.; Mahmood, N.; Beiner, M.; Androsch, R. On the effective elastic properties of isotactic polypropylene. Polymer 2019, 160, 291-302. [CrossRef]

66. Cimmino, S.; Di Lorenzo, M.L.; Di Pace, E.; Silvestre, C. Isotactic Poly(1-butene)/Hydrogenated Oligo(cyclopentadiene) Blends: Miscibility, Morphology, and Thermal and Mechanical Properties. J. Appl. Polym. Sci. 1998, 67, 1369-1381. [CrossRef]

67. Chrissafis, K.; Paraskevopoulos, K.M.; Bikiaris, D.N. Thermal degradation mechanism of poly(ethylene succinate) and poly(butylene succinate): Comparative study. Thermochim. Acta 2005, 435, 142-150. [CrossRef]

68. Mallardo, S.; De Vito, V.; Malinconico, M.; Volpe, M.G.; Santagata, G.; Di Lorenzo, M.L. Poly(butylene succinate)-based composites containing $\beta$-cyclodextrin/D-limonene inclusion complex. Eur. Polym. J. 2016, 79, 82-96. [CrossRef]

(C) 2019 by the authors. Licensee MDPI, Basel, Switzerland. This article is an open access article distributed under the terms and conditions of the Creative Commons Attribution (CC BY) license (http://creativecommons.org/licenses/by/4.0/). 